\title{
Solitary choroidal mass as the presenting sign in systemic sarcoidosis
}

\author{
R. JOSEPH OLK, ${ }^{1}$ MATTHEW J. LIPMANN, ${ }^{2}$ H. CLAY CUNDIFF, ${ }^{3}$ \\ AND JOHN DANIELS ${ }^{1}$ \\ From the ${ }^{1}$ Washington University School of Medicine, St Louis, Missouri, ${ }^{2}$ University of Cincinnati School of \\ Medicine, Cincinnati, Ohio; and ${ }^{3}$ St Francis Medical Center, Cape Girardeau, Missouri, USA
}

SUMMARY A solitary choroidal mass with an overlying neurosensory retinal detachment was seen in an otherwise healthy 25-year-old Caucasian female. Ocular and general physical examinations, serum chemistry, and pathological examination of a lymph node biopsy confirmed sarcoidosis as the cause for the choroidal mass. Treatment with systemic steroids resulted in resolution of the lesion and return of normal visual acuity.

\section{Case report}

A 25-year-old Caucasian female was seen by her local ophthalmologist and referred for retinal examination because of central blurring in her left eye for the previous 3 days. The patient noticed no redness, pain, or photophobia. Ocular history revealed one sister who was noted to have a unilateral eye defect which by history was suggestive of a coloboma. The sister was not examined. Past medical history was negative except for an upper respiratory infection one month prior to ocular examination. Four months previously the patient had given birth to a full-term, healthy child, delivered by caesarean section because of prolonged labour. After delivery the patient had a raised white blood count, the cause of which was never determined. There was no history of fever, weight loss, or anorexia. The patient abused neither drugs nor alcohol.

Ocular examination revealed best corrected visual acuity of 20/20 OD, 20/100 OS. Applanation intraocular tensions were 12/13. External examination was normal. The pupils were $4 \mathrm{~mm}$, equal, round, and reacted to light directly and consensually without an afferent defect. A muscle balance test showed orthophoria. Motility tests revealed full ductions and versions. A photo stress test showed a delay on the left greater than one minute compared with the right. American Optical colour plates showed 12 of 15 correct OD, 0 of 15 OS. An Amsler grid test showed a central scotoma OS. Slit-lamp examination of the anterior segment was unremarkable in both eyes.

Correspondence to Dr R. J. Olk, 4949 Barnes Hospital Plaza, St Louis, Missouri 63141, USA.
There was no flare or cells in the anterior chamber or anterior vitreous, and there were no iris or conjunctival nodules. No cells in the posterior vitreous could be detected on contact lens examination. The right fundus was normal. Examination of the left fundus revealed a normal disc (Fig. 1). The retinal vasculature and peripheral retinal examination was normal. A slightly depigmented choroidal lesion, $1 \times 2$ disc diameters in size, was noted in the papillomacular bundle adjacent to the optic nerve. An overlying neurosensory detachment, oval in shape and $4 \times 6$ disc diameters in size, extended from the optic disc through the foveal avascular zone.

Fluorescein angiography revealed normal retinal vasculature, multiple pinpoint areas of hyperfluorescence on the surface of the lesion, and late

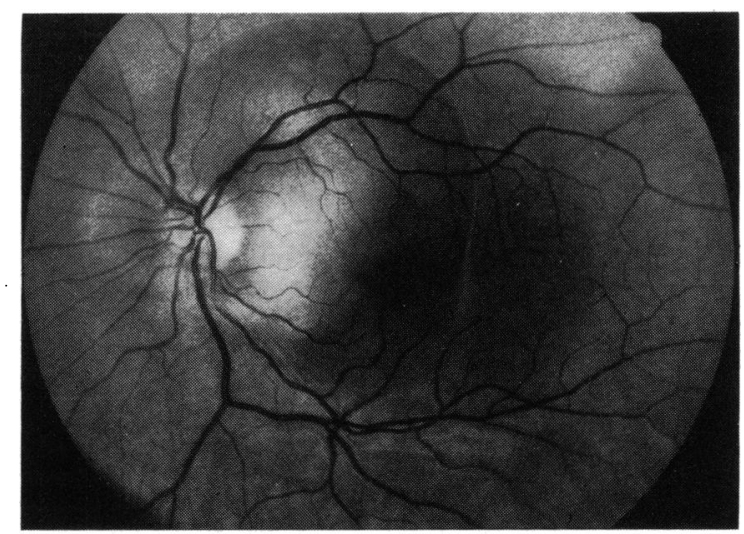

Fig. 1 Left fundus showing choroidal lesion and overlying neurosensory detachment. 


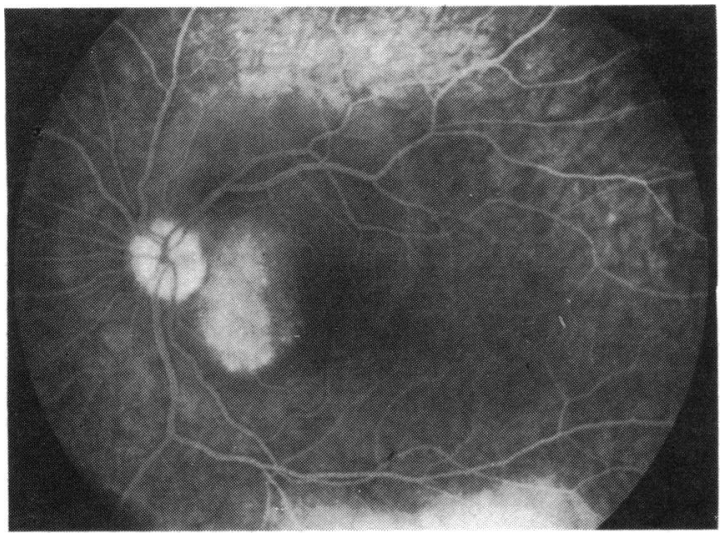

Fig. 2 Red-free photograph, OS: late phase, showing diffuse staining over lesion and collection of dye under neurosensory detachment.

diffuse staining of the entire lesion with collection of dye under the neurosensory detachment (Fig. 2). Goldmann visual fields showed a caecocentral defect in the left eye (Fig. 3). Orbital high-resolution CT scan showed a mild thickening of the soft tissues in the posterior aspect of the left globe which was enhanced by infusion (Fig. 4). Ocular ultrasound by quantitative A-scan and B-scan confirmed elevation of the neurosensory retina with fluid in the extrascleral space adjacent to the temporal aspect of the optic nerve, a pattern thought to be consistent with localised inflammatory disease.

The patient had a complete general physical examination. Chest $x$-ray showed right hilar adenopathy and an enlarged azygous node with scattered granulomata in both lung fields. A complete blood count and urine analysis were normal. The sedimentation rate was $63 \mathrm{mg} / \mathrm{h}$ (Westergren). Tests of serum chemistry showed the following abnormal values: alkaline

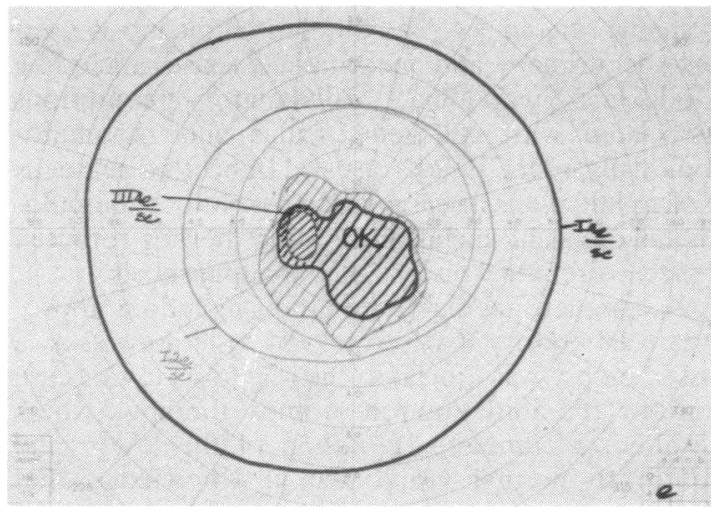

Fig. 3 Goldmann visual fields $O S$, showing caecocentral defect.

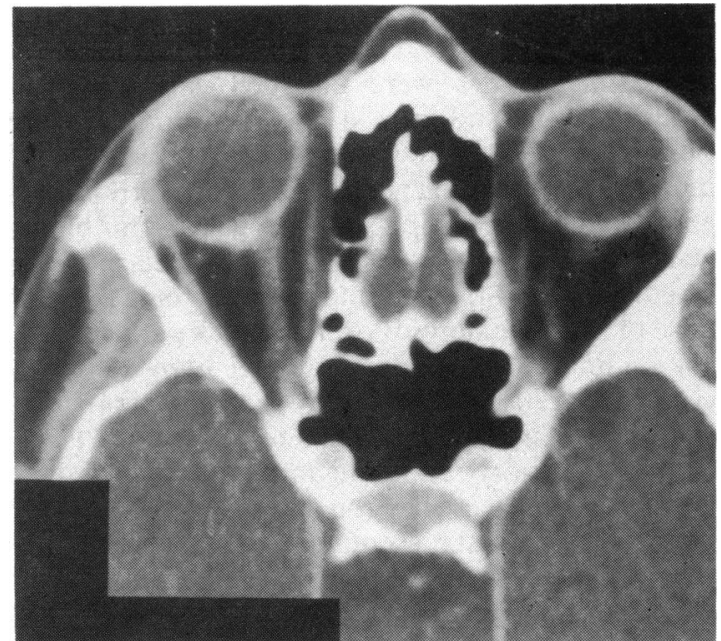

Fig. 4 High resolution orbital CT scan, post-infusion.

phosphatase (339 IU/l), $5^{\prime}$ nucleotidase (32 IU/l), and SGOT (38 IU/l). Angiotensin I converting enzyme (ACE) was $73 \mathrm{nmol} \mathrm{min}^{-1} \mathrm{ml}^{-1}$ (normal 20-68), and serum lysozyme was $15 \mathrm{ng} / \mathrm{ml}$ (normal 2·8-8). (SI conversion: $\mathrm{nmol} / \mathrm{ml}=\mu \mathrm{mol} / \mathrm{l} ; \mathrm{ng} / \mathrm{ml}=\mu \mathrm{g} / \mathrm{l}$.) Serum protein electrophoresis, antinuclear antibodies, and rheumatoid factor tests were normal. Serological tests for fungi and syphilis were negative. Intermediate PPD was nonreactive. A liver-spleen scan showed a normal liver, an enlarged spleen, and increased activity in the spleen in comparison with the liver.

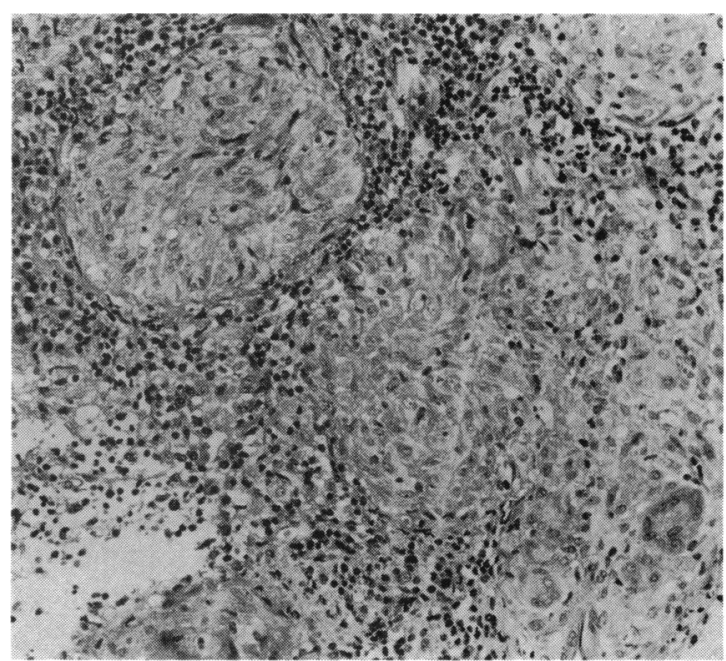

Fig. 5 Mediastinal lymph node biopsy showing noncaseating granulomatous tubercle surrounded by lymphocytes and giant cells. (Haematoxylin and eosin, $\times 58)$. 
The patient had mediastinoscopy and a lymph node biopsy. The operative report stated that the visualised mediastinal nodes were enlarged and succulent, homogeneous, and grey in colour, characteristic of sarcoid. A histopathological examination revealed multiple noncaseating granulomata with early fibrosis and surrounding lymphocytes (Fig. 5). The biopsy was believed to be consistent with a diagnosis of sarcoidosis, and the patient was begun on a tapering dose of systemic steroids over a 6-week period.

Examination after one month of therapy revealed a visual acuity of 20/30 OS and marked reduction of the choroidal lesion, with complete resolution of the overlying sensory retinal detachment. Retinal striae into the foveal avascular zone were still evident. Five months after initial presentation the visual acuity was 20/20 OS, and examination of the fundus showed only pigmentary changes at the level of the retinal pigment epithelium in the area of the previous lesion. Visual acuity one year after therapy remains 20/20 OU.

\section{Discussion}

Sarcoidosis is a chronic noncaseating granulomatous disorder of unknown aetiology affecting various organ systems, with protean symptoms. In the last 2 decades it has replaced syphilis as the 'great imitator.' Reports vary, but the disease appears to be unusually common in blacks and women and usually presents in the third and fourth decades. ${ }^{1-4}$

The known clinical ocular manifestations of sarcoidosis include nut-shaped nodules in the periorbital skin, pseudochalazia, enlargement of the lacrimal glands, keratitis sicca, nodular infiltrates of the palpebral conjunctiva, nummular and bandshaped calcification of the cornea, episcleral nodules, iridocyclitis, iris nodules, nodular vitreous opacities, periphlebitis, chorioretinitis 'en taches de bougie' (candle wax spots), optic atrophy, optic nerve and orbital tumours, papilloedema, macular oedema, extraocular muscle paralysis, and visual field defects. ${ }^{35-10}$ Although there are many case reports of ocular and orbital sarcoidosis, it is extremely rare to have isolated involvement of the posterior segment of the eye.

Ocular involvement in systemic sarcoidosis has an average estimated incidence of $25-40 \%^{11-13}$ but has been reported to be as high as $63 \% .^{14}$ The most common ocular presentation involves the uveal tract more often than the sclera, cornea, or conjunctiva. Uveal involvement characteristically is much more frequent anteriorly in the iris rather than in the ciliary body or choroid. Posterior uveitis in sarcoid is rare and is usually overshadowed by concomitant anterior uveitis. ${ }^{15}$ Gould and Kaufman stated that only onethird of all reported cases of posterior segment sarcoidosis had no apparent anterior uveitis. ${ }^{16}$ The least common sites of sarcoid infiltration are said to be the choroid and retina,${ }^{17}$ and King emphasised that sarcoid must be an extremely rare cause of localised chorioretinitis. ${ }^{18}$

Chorioretinitis was first reported in association with systemic sarcoidosis by Hudelo and Rabut, ${ }^{19}$ but this patient had accompanying iridocyclitis and bilateral choroidal infiltrates. Others ${ }^{13^{1520-23}}$ have reported cases having retinal and choroidal involvement with sarcoidosis, but in all cases there were other associated ocular findings. Goldberg and Newell reported 2 cases with single lesions of the fundus but primarily involving retinal infiltration with accompanying retinal vascular changes. ${ }^{15}$ They speculated that perhaps in those cases of retinal infiltration with sarcoid the retinal vascular changes might precede the appearance of the visible fundus mass, as was directly observed in one of their cases.

Chumbley and Kearns reported 4 cases in which retinal findings were the exclusive ocular manifestation of sarcoidosis. ${ }^{23}$ They emphasised that in posterior segment sarcoidosis retinal involvement was much more frequent than choroiditis, choroidal or optic nerve granulomas, or lesions of the vitreous.

Many cases of optic disc infiltration and optic disc oedema secondary to ocular sarcoid as well as sarcoid tumours of the optic nerve have been reported. ${ }^{152224-29}$ In addition the presence of a chorioretinal mass projecting into the vitreous has been reported, ${ }^{13-15}{ }^{30}$ but in all these cases there have been associated changes in the overlying retinal vasculature or other associated findings consistent with ocular sarcoidosis.

A recent report ${ }^{31}$ cites 2 cases of sarcoid granuloma of the choroid. However, one case occurred in a patient with previously diagnosed systemic sarcoidosis. The authors are not aware of any other previously published case reports of a solitary choroidal granuloma as the sole presenting sign in systemic sarcoidosis. The differential diagnosis must include primary and metastatic disease, including Hodgkin's lymphoma, inflammatory conditions associated with collagen-vascular and rheumatological disorders, Eales's disease, Behçet's disease, as well as infectious diseases such as syphilis, tuberculosis, cytomegalic inclusion retinitis, herpes retinitis, brucellosis, fungal disease, and toxoplasmosis.

A complete medical evaluation including appropriate laboratory and serological tests as well as a tissue biopsy was crucial to the diagnosis in this case and to the initiation of prompt therapy, which resulted in complete resolution of the lesion and return to normal visual acuity. Knowledge that systemic sarcoidosis can present as a solitary choroidal mass may be of importance to ophthalmologists. 
The authors acknowledge the assistance of Morton Smith, MD, who reviewed the histopathology from the lymph node biopsy, and William A. Hart, MD, who performed the quantitative A- and B-scan ultrasonography.

\section{References}

1 Nielsen RH. Ocular sarcoidosis. Arch Ophthalmol 1959; 61: 657-63.

2 Obenauf CD, Shaw HE, Sydnor CF, Klintworth GK. Sarcoidosis and its ophthalmic manifestations. Am J Ophthalmol 1978; 86: 648-55.

3 Crick RP, Hoyle C, Smellie H. The eyes in sarcoidosis. Br J Ophthalmol 1961; 45: 461-81.

4 Iwata K, Nanba K, Sobue K, Abe H, et al. Ocular sarcoidosis: evaluation of intraocular findings. Ann NY Acad Sci 1976; 278: 445-54.

5 Zimmerman LE, Maumenee AE. Ocular aspects of sarcoidosis. Am Rev Resp Dis 1961; 84: 38-44.

6 Wilmer WH. Tubercle-like nodules of episclera and eyelids, bilateral. Am J Ophthalmol 1934; 17: 99-106.

7 James DG. Ocular sarcoidosis. Am J Med 1959; 26: 331-9.

8 Levitt JM. Boeck's sarcoid with ocular localization. Arch Ophthalmol 1941; 26: 358-88.

9 Franceschetti A, Babel J. La choriorétinite en 'taches de bougie' manifestation de la maladie de Besnier-Boeck. Ophthalmologica 1949; 118: 701-10.

10 James DG, Zatouroff MA, Trowell J, Rose FC. Papilloedema in sarcoidosis. Br J Ophthalmol 1967; 51: 526-9.

11 Klein M, Calvert RJ, Joseph WE, Smith E. Rarities in ocular sarcoidosis. Br J Ophthalmol 1955; 39: 416-21.

12 Letocha CE, Shields JA, Goldberg RE. Retinal changes in sarcoidosis. Can J Ophthalmol 1975; 10: 184-92.

13 Walsh FB. Ocular importance of sarcoid. Its relation to uveoparotid fever. Arch Ophthalmol 1939; 21: 421-38.

14 Ozazewski JC, Bennett V. Ocular sarcoidosis. Report of three cases. Am J Ophthalmol 1952; 35: 547-50.
15 Goldberg MS, Newell FW. Sarcoidosis with retinal involvement. Arch Ophthalmol 1944; 32: 93-6.

16 Gould H, Kaufman HE. Sarcoid of the fundus. Arch Ophthalmol $1961 ; 65: 453-6$.

17 Laval J. Ocular sarcoidosis. Am J Ophthalmol 1952; 35: 551-4.

18 King MJ. Ocular lesions of Boeck's sarcoid. Trans Am Acad Ophthalmol Soc 1939; 37: 422-58.

19 Hudelo L, Rabut R. Lupoides disseminées de Boeck. Bull Soc Fr Derm Syph 1925; 32: 108-9.

20 Horton R, Lincoln NS, Pinner M. Noncaseating tuberculosis. Am Rev Respir Dis 1939; 39: 186-203.

21 Meyer FW. Augentuberkulose und lymphogranulomatosis benigna. Klin Monatsbl Augenheilkd 1939; 102: 76-88.

22 Reis W, Rothfeld J. Tuberkulide des Schnerven als Komplikation von Hautsarkoiden vom Typus Darier-Roussy. Arch Ophthalmol 1931; 126: 357-66.

23 Chumbley LC, Kearns TP. Retinopathy of sarcoidosis. Am J Ophthalmol 1972; 73: 123-31.

24 Statton R, Blodi FC, Hanigan J. Sarcoidosis of the optic nerve Arch Ophthalmol 1964; 71: 834-6.

25 Morax PV. Les localisations neuro-oculaires de la reticuloendotheliose de Besnier-Boeck-Schaumann. Ann Oculist (Paris) 1956; 189: 73-91.

26 Kojima K. Fundus involvement in sarcoidosis. J Clin Ophthalmol 1969; 23: 790-3.

27 von Mackensen G. Veranderungen am Augenintergrund bei Besnier-Boeck-Schaumannscher Erkemkung. Klin Monatsb Augenheilkd 1958; 121: 51-63.

28 Brunste E. Ocular sarcoidosis. Dan Med Bull 1958; 5: 217-27.

29 Laties AM, Scheie HG. Sarcoid granuloma of the optic disk: evolution of multiple small tumors. Trans Am Ophthalmol Soc 1970: 68: 219-33.

30 Woods AC, Guyton JS. Role of sarcoidosis and of brucellosis in uveitis. Arch Ophthalmol 1944; 31: 469-80.

31 Marcus DF, Bovino JA, Burton TC. Sarcoid granuloma of the choroid. Ophthalmology 1982; 89: 1326-30. 